\title{
In vivo evaluation of BACtrackR Skyn: a discrete wrist-worn transdermal alcohol monitoring device marketed to the public
}

\author{
Aaron Olson
}

December 1, 2021

\begin{abstract}
A discrete wrist-worn transdermal alcohol monitoring device, the BACtrack $($ Skyn, was evaluated in a subject over three drinking sessions. The relationship between transdermal alcohol concentration (TAC) and breath alcohol concentration (BrAC) was evaluated. The relationship amongst contemporaneous $\mathrm{TAC} / \mathrm{BrAC}$ measurements revealed an $\mathrm{R}^{2}$ of 0.65 , while the relationship in the 45-minute post-drinking phase revealed an $\mathrm{R}^{2}$ of 0.89 . Results obtained show promise for its use. Further research is needed with many subjects in realworld drinking situations.
\end{abstract}

\section{Introduction}

In March of 2015, the National Institute of Health issued a challenge to create a "Wearable Alcohol Sensor Challenge" that could discretely measure alcohol concentrations in real-time (1). The winner of the challenge received $\$ 200,000$

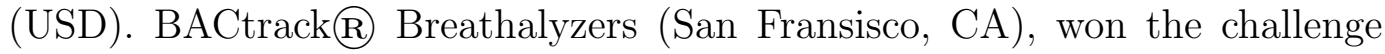
by creating a prototype of a discrete wrist-worn transdermal alcohol monitoring device known as the BACtrack@ Skyn (2). In September of 2019, BACtrack(r) Skyn was made available for research purposes (3). This study evaluated the relationship between breath alcohol (BrAC) and transdermal al- 
cohol (TAC) measurements recorded with the BACtrack(r) Skyn in a subject during three drinking sessions.

Continuous transdermal alcohol monitoring may be useful for self-tracking (4; $5 ; 6)$, medicine $(7 ; 8)$, remote monitoring of alcohol use $(9 ; 10)$, traffic safety (11), law (12), and research $(13 ; 14)$. Most of the current generation of transdermal alcohol monitoring biosensors are bulky devices marketed towards criminal law enforcement for the monitoring of repeat alcohol-related offenses $(15 ; 16 ; 17 ; 18 ; 13)$. More recently, discrete transdermal alcohol sensors have been developed for continuous monitoring of alcohol use $(19 ; 20 ; 21$; $22 ; 23 ; 24 ; 25 ; 26 ; 27)$.

\section{Methods and Materials}

The BACtrack(r) Skyn (BACtrack Breathalyzers, San Fransisco, California, USA) device contains an electrochemical fuel cell to continuously monitor alcohol vapors emanating from the skin. It records measurements every 20 seconds and transmits data via Bluetooth(r) to an app on the user's smartphone. Photos of the device are shown in figures 1 and 2 .

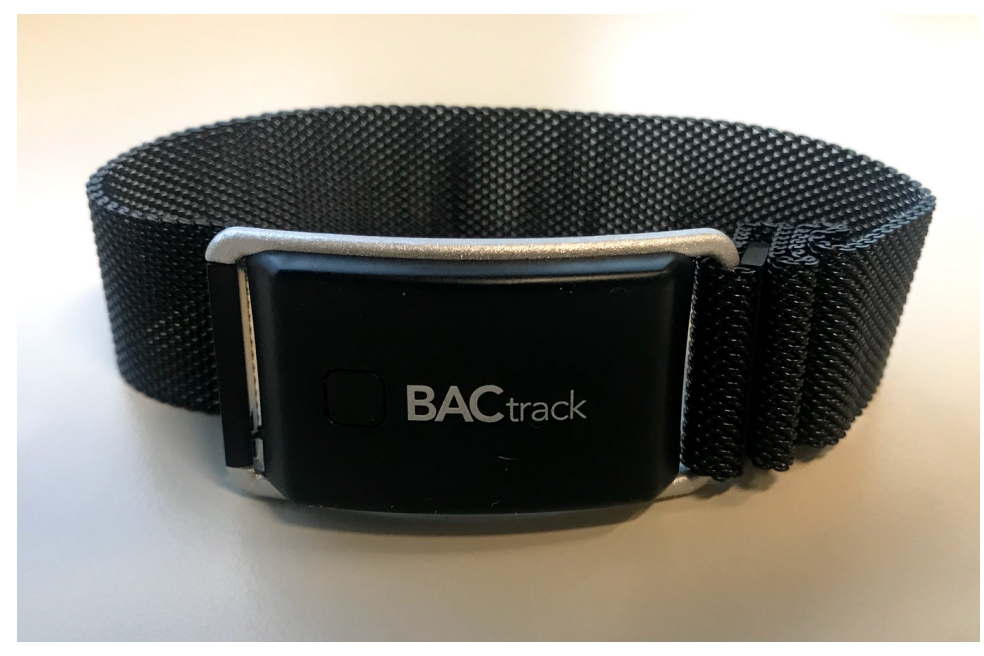

Figure 1: BACtrack@ Skyn 


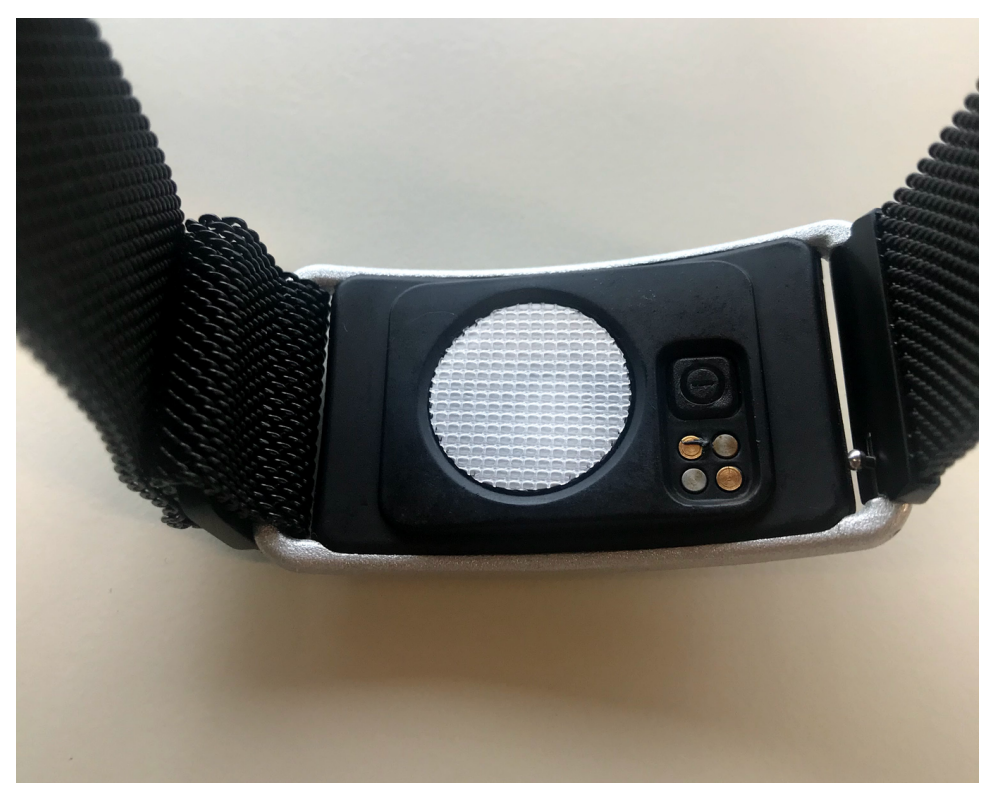

Figure 2: BACtrack@ Skyn sensor

Contemporaneous TAC/BrAC measurements were collected in a subject during three drinking sessions. After a fast of at least 4-hours, a subject (the author) drank a mixture of orange juice and 80-proof vodka ad libitum during a 5-minute period. BrAC measurements began 15-minutes after the end of drinking to ensure residual mouth alcohol did not bias the BrAC measurements $(28 ; 29)$. BrAC measurements were taken approximately every 16 minutes. Transdermal alcohol measurements were recorded every 20 seconds. A total of 43 Contemporaneous TAC/BrAC measurements were analyzed from three drinking sessions lasting 1.4, 2.0, and 8.1 hours.

An electrochemical breath alcohol analyzer, the BACtrack(r) Mobile Pro (BACtrack Breathalyzers, San Fransisco, California, USA) was used to measure $\mathrm{BrAC}(30 ; 31 ; 32)$. Accuracy checks were performed with the breath alcohol analyzer prior to use at reference vapors of $0.007,0.065,0.080$, and $0.162 \mathrm{~g} / 210 \mathrm{~L}$ (g/dl blood alcohol [BAC] equivalent). Results fell within 0.002 $\mathrm{g} / 210 \mathrm{~L}$ of reference standards. 


\section{Results}

The mean time-to-peak BrAC was 33-minutes, while the mean time-to-peak TAC was 60-minutes. The relationship between TAC/BrAC for all measurements $(n=43)$ revealed an $R^{2}$ of 0.65 . A scatterplot of the relationship is shown in figure 3 . The $\mathrm{TAC} / \mathrm{BrAC}$ relationship during the 45-minute postdrinking phase $(n=37)$ revealed an $R^{2}$ of 0.89 . Figure 4 shows a scatterplot of the $\mathrm{TAC} / \mathrm{BrAC}$ relationship in the post-45-minute drinking time period.

Figure 5 shows a line graph plotting the TAC/BrAC measurements taken over an 8 hour period.

TAC vs. BrAC

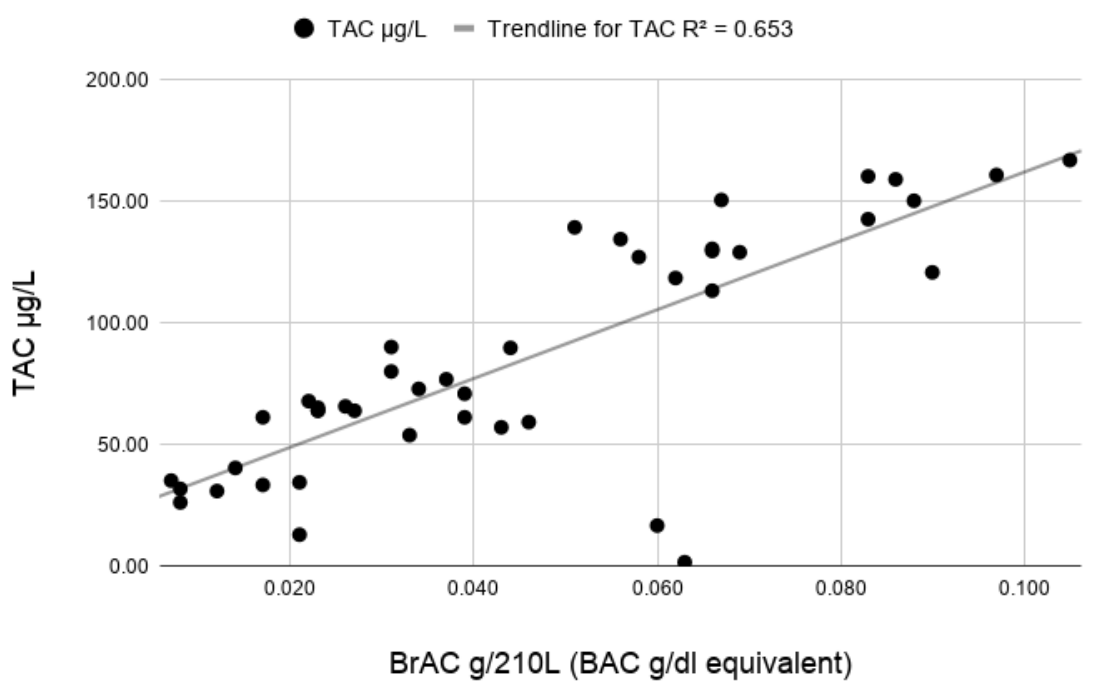

Figure 3: TAC vs. BrAC for all measurements 
TAC vs. BrAC 45-min post-drinking

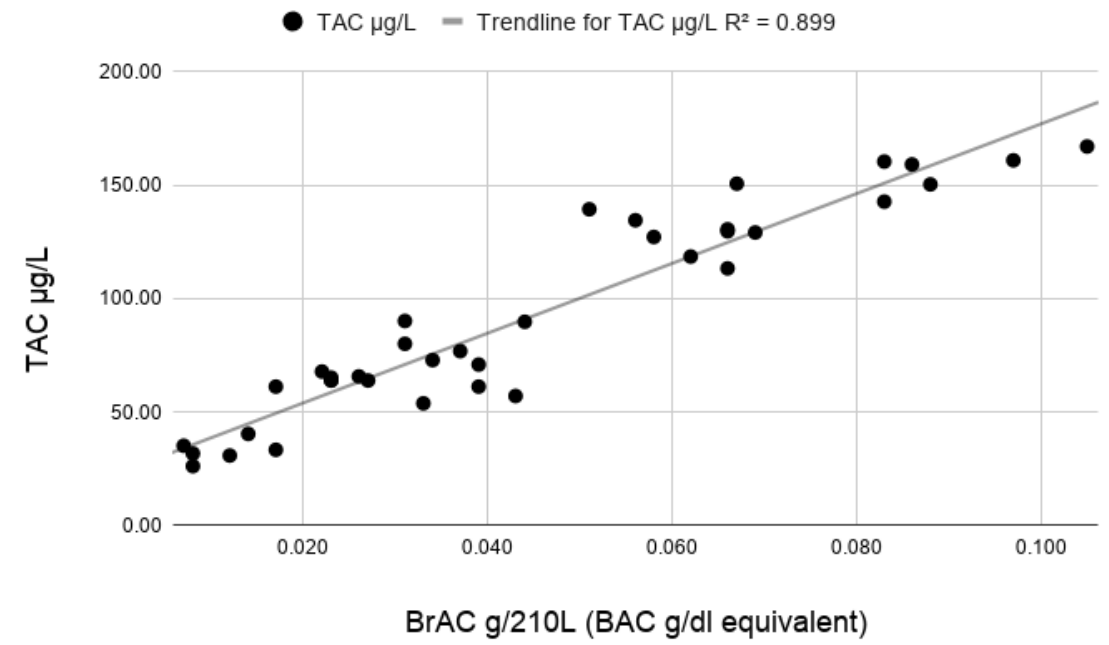

Figure 4: TAC vs. BrAC in the 45-min post-drinking time period

TAC/BrAC over an $8 \mathrm{hr}$ period

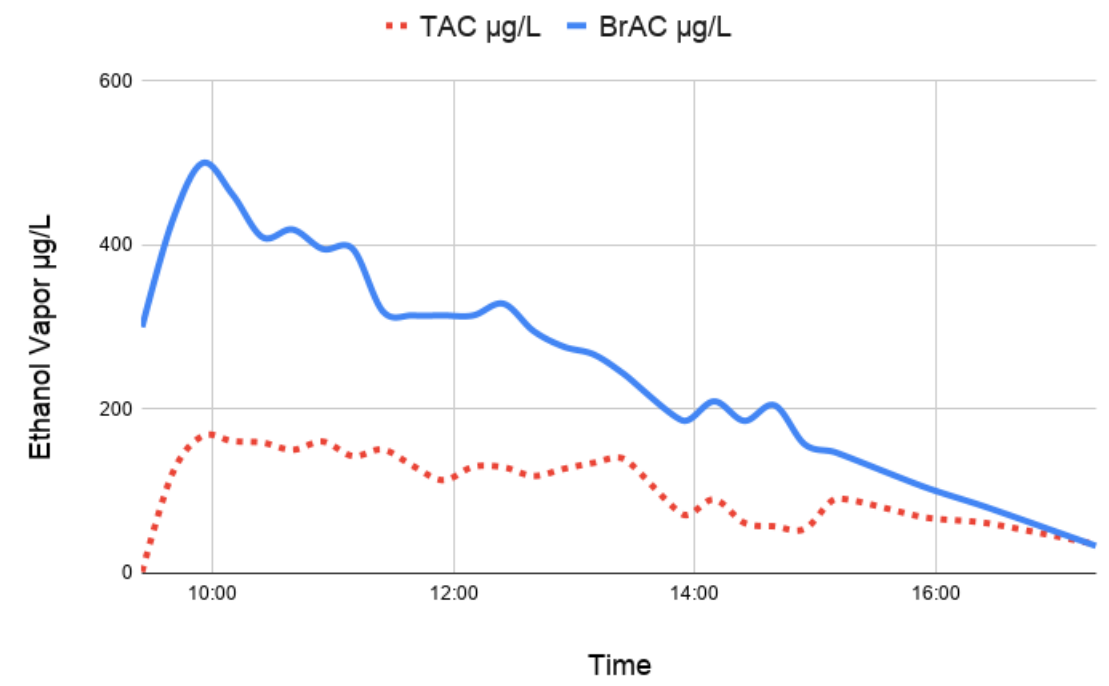

Figure 5: TAC/BrAC over an 8 hr period 


\section{Discussion}

Differences in time delays in peak TAC relative to peak $\mathrm{BrAC}$ have been documented in the literature $(33 ; 34)$, and shown to be dose-dependent (11). Time-to-peak alcohol concentration is known to vary by the matrix (35) and by the type of transdermal device used (36). Similar time delays have been documented in time-to-peak urine alcohol vs. time-to-peak BAC, where peak urine alcohol is obtained sometime after peak BAC (37).

In addition to time delays, venous/arterial compartmental differences in alcohol concentration have been documented in the literature $(38 ; 39)$. Venous/arterial compartmental differences can affect the ratio between $\mathrm{BrAC}$ to BAC during the absorptive phase of alcohol pharmacokinetics (40). The compartmental differences could affect the TAC/BrAC relationship and may explain the higher $\mathrm{R}^{2}$ value (0.89) in the TAC/BrAC relationship during the 45 -minute post-drinking phase. It is also plausible that transdermal alcohol devices may be more useful when used as a screening tool, rather than a predictive measurement of $\mathrm{BrAC}$ or $\mathrm{BAC}(41 ; 42 ; 43)$.

\section{Limitations}

The scope of this study was limited to a single subject. More work needs to be done in many subjects under realistic social drinking circumstances. In addition, more research needs to be done on the effects of active perspiration through exercise, long-term fouling of the sensor (44; 45), changes in skin temperature, and the effect of topical substances such as lotions and perfumes.

\section{Conclusions}

The results obtained from the BACtrack $\cap$ Skyn transdermal alcohol monitoring device show promise for its use (46). The relationship between TAC/BrAC was highly correlated, especially in the post-45-minute time period after drink- 
ing. Further research is needed under real-world social drinking conditions with many subjects.

\section{Conflicts of Interest}

None.

\section{Declarations}

All statements and opinions are solely that of the author.

\section{Hosted file}

BACtrack Skyn Supplementary Data.xlsx available at https: //authorea.com/users/308674/articles/443002-in-vivo-evaluationof-bactrack-skyn-a-discrete-wrist-worn-transdermal-alcoholmonitoring-device-marketed-to-the-public

\section{References}

1. NIH holds competition to create better wearable alcohol biosensor [Internet]. National Institutes of Health. 2015. Available at: https://www.nih.gov/news-events/news-releases/nih-holdscompetition-create-better-wearable-alcohol-biosensor

2. NIAAA selects winners of its Wearable Alcohol Biosensor Challenge [Internet]. National Institutes of Health (NIH). 2016. Available at: https://www.nih.gov/news-events/news-releases/niaaa-selectswinners-its-wearable-alcohol-biosensor-challenge

3. BACtrack Skyn ${ }^{\top M}$ - The World's 1st Wearable Alcohol Monitor [Internet]. https://skyn.bactrack.com/; Available at: https://skyn. bactrack.com/ 
4. Gimpe H, Nißen M, Görlitz RA. Quantifying the quantified self: A study on the motivation of patients to track their own health. In: International Conference on Information Systems (ICIS 2013): Reshaping Society Through Information Systems Design [Internet]. 2013. p. 3286-301. Available at: https://www.semanticscholar.org/paper/Quantifyingthe-Quantified-Self\%3A-A-Study-on-the-of-Gimpel-Ni\%C3\%9Fen/ 7ccbe2e99078317a8657a2d362cdeb755b323cf 4

5. Pfeiffer J, Entress-Fuersteneck M von, Nils U, Buchwald A. Quantifyme: Consumer Acceptance of Wearable Self-tracking Devices. ECIS [Internet]. 2016; Available at: https://www.semanticscholar.org/paper/ da4afa24ef8e277f8bbf2e74e942ad0b939d14f1

6. Lupton D. Self-tracking health and medicine. Health Sociology Review [Internet]. November 2016;26(1):1-5. Available at: https://doi.org/10. $1080 \% 2 \mathrm{~F} 14461242.2016 .1228149$

7. Indig D, Copeland J, Conigrave K, Rotenko I. Why are alcoholrelated emergency department presentations under-detected? An exploratory study using nursing triage text. Drug and Alcohol Review [Internet]. November 2008;27(6):584-90. Available at: https://doi.org/10.1080\% 2F09595230801935680

8. Kim J, Campbell AS, Ávila BE-F de, Wang J. Wearable biosensors for healthcare monitoring. Nature Biotechnology [Internet]. February 2019;37(4):389-406. Available at: https://doi.org/10.1038\%2Fs41587019-0045-y

9. Alessi SM, Barnett NP, Petry NM. Objective continuous monitoring of alcohol consumption for three months among alcohol use disorder treatment outpatients. Alcohol [Internet]. December 2019;81:131-8. Available at: https://doi.org/10.1016\%2Fj.alcohol.2019.01.008

10. Gordon A, Jaffe A, McLellan AT, Richardson G, Skipper G, Sucher M, et al. How Should Remote Clinical Monitoring Be Used to Treat Alcohol Use Disorders?. Journal of Addiction Medicine [Internet]. 2017;11(2):145-53. 
Available at: https://doi.org/10.1097\%2Fadm.0000000000000288

11. Webster GD, Gabler HC. Feasibility of transdermal ethanol sensing for the detection of intoxicated drivers.. Annu Proc Assoc Adv Automot Med [Internet]. 2007;51:449-64. Available at: https://www.ncbi.nlm.nih.gov/ $\mathrm{pmc/articles/PMC3217504/}$

12. Robertson R, Vanlaar W, Simpson HM. Continuous transdermal alcohol monitoring: A Primer for criminal justice professionals [Internet]. Traffic Injury Research Foundation; 2006. Available at: https://tirf.ca/wpcontent/uploads/2017/02/CTAM_Primer_Booklet.pdf

13. Alessi SM, Barnett NP, Petry NM. Experiences with SCRAMx alcohol monitoring technology in 100 alcohol treatment outpatients. Drug and Alcohol Dependence [Internet]. September 2017;178:417-24. Available at: https: //doi.org/10.1016\%2Fj.drugalcdep.2017.05.031

14. Wang Y, Fridberg DJ, Leeman RF, Cook RL, Porges EC. Wrist-worn alcohol biosensors: Strengths limitations, and future directions. Alcohol [Internet]. December 2019;81:83-92. Available at: https://doi.org/10.1016\% 2Fj.alcohol.2018.08.013

15. Marques PR, McKnight AS. Field and Laboratory Alcohol Detection With 2 Types of Transdermal Devices. Alcoholism: Clinical and Experimental Research [Internet]. April 2009;33(4):703-11. Available at: https://doi. org/10.1111\%2F j . 1530-0277.2008.00887.x

16. Roache JD, Karns TE, Hill-Kapturczak N, Mullen J, Liang Y, Lamb RJ, et al. Using Transdermal Alcohol Monitoring to Detect Low-Level Drinking. Alcoholism: Clinical and Experimental Research [Internet]. May 2015;39(7):1120-7. Available at: https://doi.org/10.1111\%2Facer. 12750

17. Marques PR, McKnight AS, Others. Evaluating transdermal alcohol measuring devices [Internet]. United States. National Highway Traffic Safety Administration; 2007. Available at: https://rosap.ntl.bts.gov/view/dot/ 1793 
18. McKnight AS, Fell JC, Auld-Owens A. Transdermal alcohol monitoring: Case studies [Internet]. National Highway Traffic Safety Administration; 2012. Report No.: DOT HS 811 603. Available at: https://www.nhtsa.gov/ staticfiles/nti/pdf/811603.pdf

19. Hair ME, Gerkman R, Mathis AI, Halámková L, Halámek J. Noninvasive Concept for Optical Ethanol Sensing on the Skin Surface with Camera-Based Quantification. Anal Chem [Internet]. December 2019;91(24):15860-5. Available at: http://dx.doi.org/10.1021/acs . analchem.9b04297

20. Lansdorp B, Ramsay W, Hamidand R, Strenk E. Wearable Enzymatic Alcohol Biosensor. Sensors [Internet]. May 2019;19(10). Available at: http: //dx.doi.org/10.3390/s19102380

21. Campbell AS, Kim J, Wang J. Wearable Electrochemical Alcohol Biosensors. Curr Opin Electrochem [Internet]. August 2018;10:126-35. Available at: http://dx.doi.org/10.1016/j.coelec.2018.05.014

22. Kim J, Jeerapan I, Imani S, Cho TN, Bandodkar A, Cinti S, et al. Noninvasive Alcohol Monitoring Using a Wearable Tattoo-Based IontophoreticBiosensing System. ACS Sensors [Internet]. July 2016;1(8):1011-9. Available at: https://doi.org/10.1021\%2Facssensors. 6b00356

23. Gamella M, Campuzano S, Manso J, Rivera GG de, López-Colino F, Reviejo AJ, et al. A novel non-invasive electrochemical biosensing device for in situ determination of the alcohol content in blood by monitoring ethanol in sweat. Analytica Chimica Acta [Internet]. January 2014;806:1-7. Available at: https://doi.org/10.1016\%2Fj .aca.2013.09.020

24. Mohan AMV, Windmiller JR, Mishra RK, Wang J. Continuous minimallyinvasive alcohol monitoring using microneedle sensor arrays. Biosensors and Bioelectronics [Internet]. May 2017;91:574-9. Available at: https://doi. org/10.1016\%2Fj. bios . 2017.01.016

25. Lawson B, Martini-Laithier V, Fiorido T, Annanouch F, Burtey S, CasséPerrot C, et al. Transdermal Alcohol Measurements Using MOX Sensors in 
Clinical Trials. Proceedings [Internet]. August 2017;1(4):431. Available at: https://doi .org/10.3390\%2Fproceedings 1040431

26. Carter MT, Findlay MW, Peaslee D, Ploense L, Meulendyk BJ, Devine E, et al. Transdermal Alcohol Monitoring with a Printed Amperometric Gas Sensor. ECS Meeting Abstracts [Internet]. May 2020;MA2020-01(27):2010-. Available at: https://doi.org/10.1149\%2Fma2020-01272010mtgabs

27. Umasankar Y, Jalal AH, Gonzalez PJ, Chowdhury M, Alfonso A, Bhansali S. Wearable alcohol monitoring device with auto-calibration ability for high chemical specificity. In: 2016 IEEE 13th International Conference on Wearable and Implantable Body Sensor Networks (BSN) [Internet]. IEEE; 2016. Available at: https://doi.org/10.1109\%2Fbsn.2016.7516287

28. Anstie FE. Prognosis and treatment of certain acute diseases. Lancet [Internet]. September 1867;90(2300):385-7. Available at: http://www . sciencedirect.com/science/article/pii/S0140673602550054

29. Gullberg RG. The elimination rate of mouth alcohol: mathematical modeling and implications in breath alcohol analysis.. J Forensic Sci. 1992;37:1363-72.

30. Riordan BC, Scarf D, Moradi S, Flett JAM, Carey KB, Conner TS. The accuracy and promise of personal breathalysers for research: Steps toward a cost-effective reliable measure of alcohol intoxication?. Digit Health. January 2017;3:2055207617746752.

31. Olson A. In vitro evaluation of BACtrack $\AA$ 's smartphone-connected personal breath alcohol analyzers. Authorea [Internet]. November 2021; Available at: https://doi.org/10.22541/au.163776893.31418908/v1

32. Delgado MK, Shofer F, Wetherill R, Curtis B, Hemmons J, Spencer E, et al. Accuracy of Consumer-marketed smartphone-paired alcohol breath testing devices: A laboratory validation study. Alcoholism: Clinical and Experimental Research [Internet]. May 2021;45(5):1091-9. Available at: https://doi.org/10.1111\%2Facer. 14597 
33. Karns-Wright TE, Roache JD, Hill-Kapturczak N, Liang Y, Mullen J, Dougherty DM. Time Delays in Transdermal Alcohol Concentrations Relative to Breath Alcohol Concentrations. Alcohol and Alcoholism [Internet]. August 2016;52(1):35-41. Available at: https://doi.org/10.1093\%2Falcalc\% 2Fagw058

34. Anderson JC, Hlastala MP. The kinetics of transdermal ethanol exchange. Journal of Applied Physiology [Internet]. February 2006;100(2):649-55. Available at: https://doi.org/10.1152\%2Fjapplphysiol.00927.2005

35. Jones AW. Alcohol its analysis in blood and breath for forensic purposes, impairment effects, and acute toxicity. Wiley Interdisciplinary Reviews: Forensic Science [Internet]. July 2019;1(6). Available at: https: //doi.org/10.1002\%2Fwfs2.1353

36. Fairbairn CE, Kang D. Temporal Dynamics of Transdermal Alcohol Concentration Measured via New-Generation Wrist-Worn Biosensor. Alcoholism: Clinical and Experimental Research [Internet]. August 2019;43(10):2060-9. Available at: https://doi.org/10.1111\%2Facer.14172

37. Jones AW. Urine as a Biological Specimen for Forensic Analysis of Alcohol and Variability in the Urine-to-Blood Relationship. Toxicological Reviews [Internet]. 2006;25(1):15-35. Available at: https://doi.org/10.2165\% 2F00139709-200625010-00002

38. Jones AW, Norberg A, Hahn RG. Concentration-time profiles of ethanol in arterial and venous blood and end-expired breath during and after intravenous infusion. J Forensic Sci [Internet]. November 1997;42(6):1088-94. Available at: https://www.ncbi.nlm.nih.gov/pubmed/9397551

39. Jones AW, Andersson L. Comparison of ethanol concentrations in venous blood and end-expired breath during a controlled drinking study. Forensic Sci Int [Internet]. March 2003;132(1):18-25. Available at: http://dx.doi.org/ $10.1016 / \mathrm{s} 0379-0738(02) 00417-6$

40. Jones AW. Reliability of breath-alcohol measurements during the absorp- 
tion phase.. Clin Chem. 1987;33:2128-30.

41. Hawthorne JS, Wojcik MH. Transdermal Alcohol Measurement: A Review of the Literature. Canadian Society of Forensic Science Journal [Internet]. January 2006;39(2):65-71. Available at: https://doi.org/10.1080\% 2F00085030.2006.10757138

42. Swift R. Direct measurement of alcohol and its metabolites. Addiction [Internet]. December 2003;98:73-80. Available at: https://doi.org/10. $1046 \% 2 \mathrm{Fj}$. 1359-6357.2003.00605.x

43. Sakai JT, Mikulich-Gilbertson SK, Long RJ, Crowley TJ. Validity of Transdermal Alcohol Monitoring: Fixed and Self-Regulated Dosing. Alcoholism: Clinical and Experimental Research [Internet]. January 2006;30(1):26-33. Available at: https://doi .org/10.1111\%2Fj.1530$0277.2006 .00004 . \mathrm{x}$

44. Allan JTS, Rahman MR, Easton EB. The influence of relative humidity on the performance of fuel cell catalyst layers in ethanol sensors. Sensors and Actuators B: Chemical [Internet]. February 2017;239:120-30. Available at: https://doi.org/10.1016\%2Fj .snb. 2016.07.156

45. Moisture Control in a Transdermal Blood Alcohol Monitor. U.S. Patent US 2009/0182216 A1 [Internet]. 16AD. Available at: https://patents. google.com/patent/US20090182216A1/en

46. Wang Y, Fridberg DJ, Shortell DD, Leeman RF, Barnett NP, Cook RL, et al. Wrist-worn alcohol biosensors: Applications and usability in behavioral research. Alcohol [Internet]. May 2021;92:25-34. Available at: http://dx . doi.org/10.1016/j.alcohol.2021.01.007 